\title{
Major virulence factors, VacA and CagA, are commonly positive in Helicobacter pylori isolates in Japan
}

S Maeda, K Ogura, H Yoshida, F Kanai, T Ikenoue, N Kato, Y Shiratori, M Omata

\begin{abstract}
Background-VacA and CagA proteins have been reported to be major virulence factors of Helicobacter pylori. However, antibodies against these proteins are frequently found in the sera of Japanese patients regardless of their gastroduodenal status.
\end{abstract}

Aim-To evaluate the expression of VacA and CagA proteins by $\mathrm{H}$ pylori strains isolated in Japan.

Methods-By using specific antibodies raised against recombinant $\operatorname{VacA}$ and CagA proteins, the expression of $\operatorname{Vac} A$ and CagA was evaluated in $68 \mathrm{H}$ pylori strains isolated from Japanese patients; a vacuolating assay and genotyping of the $v a c A$ gene were also used in the evaluation. The results were analysed in relation to the gastroduodenal diseases of the hosts.

Results-VacA and CagA proteins were expressed in $59 / 68(87 \%)$ and in $61 / 68$ $(90 \%)$ isolates respectively. The vacuolating assay was positive in 57/68 (84\%) isolates, indicating that most immunologically VacA positive strains produced active cytotoxin. The prevalence of infection with strains expressing CagA and positive for vacuolating activity (Type I) was very high, 54/68 (79\%), irrespective of the gastroduodenal status of the host.

Conclusion-Most $H$ pylori isolates in Japan are positive for vacuolating cytotoxin and $\operatorname{CagA}$, and thus these virulence factors cannot be used as markers to discern the risk of developing serious gastroduodenal pathologies in the hosts. However, the high prevalence of infection with strains positive for vacuolating cytotoxin and CagA may contribute to the characteristics of $\boldsymbol{H}$ pylori infection in Japan.

(Gut 1998;42:338-343)

Keywords: VacA; Helicobacter pylori; CagA; ulcer; non-ulcer dyspepsia

Helicobacter pylori is a Gram negative microaerophilic bacterium that can infect human gastric mucosa. ${ }^{1}$ The organism is closely associated with not only active gastritis but also peptic ulcers and gastric cancer. ${ }^{2-5}$ The prevalence of $H$ pylori infection is high world wide, and about $80 \%$ of the general population are infected at age $40-50$ in Japan. ${ }^{6}$ However, the infection leads to peptic ulcers or gastric cancer in only a small subset of infected patients. Although the pathogenesis of $H$ pylori related gastroduodenal diseases is not well understood, there are several putative virulence factors of $H$ pylori that may contribute to the exacerbation of mucosal damage.

Vacuolating cytotoxin, which induces vacuolation in cultured eukaryotic cells, is secreted by about $50 \%$ of $H$ pylori isolates in Western countries. Infection with vacuolating cytotoxin positive strains is reported to be associated with particular gastroduodenal diseases. ${ }^{7-11}$ For instance, Figura et al showed that strains with vacuolating cytotoxin activity were found in 16 of $24(67 \%)$ patients with peptic ulcers but in only 16 of $53(30 \%)$ patients without. The cytotoxin is encoded by the vac $A$ gene, ${ }^{12-15}$ and thus is also called VacA protein.

CagA protein is another putative virulence factor, encoded by the cag $A$ gene (cytotoxin associated gene A). ${ }^{16} 17$ It has been reported that this gene is present in about $60 \%$ of $H$ pylori isolates, and nearly all cag $A$ gene positive strains express the protein. ${ }^{18}$ Although the function of CagA protein is not known, the protein has been reported to be associated with particular gastroduodenal diseases. ${ }^{19-22}$ Ching et $a l^{2}$ found serum anti-CagA antibody in 165 of 197 (84\%) patients with duodenal ulcer, but in only 25 of 45 (56\%) patients with non-ulcer dyspepsia. Recently, CagA positive $H$ pylori strains have been shown to be associated with interleukin-8 (IL-8) induction in gastric epithelium. Neutrophilic infiltration into the gastric epithelium, which is characteristic of $H$ pylori infection, may be due to increased production of IL-8. CagA protein may thus be related to gastric inflammation and gastroduodenal diseases. ${ }^{23}$

Expression of CagA protein is closely associated with that of vacuolating cytotoxin, ${ }^{18}$ although the underlying mechanism is not understood. Thus Xiang et $a l^{19}$ classified $H$ pylori strains into two groups, Type I and Type II. They and others reported that the Type I strains, which are positive for both vacuolating cytotoxin and CagA, were strongly associated with peptic ulcer diseases in the host. ${ }^{1924}$

However, there have been few reports on the expression of VacA and CagA proteins in $H$ pylori strains isolated in regions other than Western countries. In previous studies, we made recombinant CagA and VacA proteins and investigated serum anti-CagA and antiVacA antibodies in Japanese patients with $H$ pylori infection. These studies showed unexpectedly high seropositivity for both 


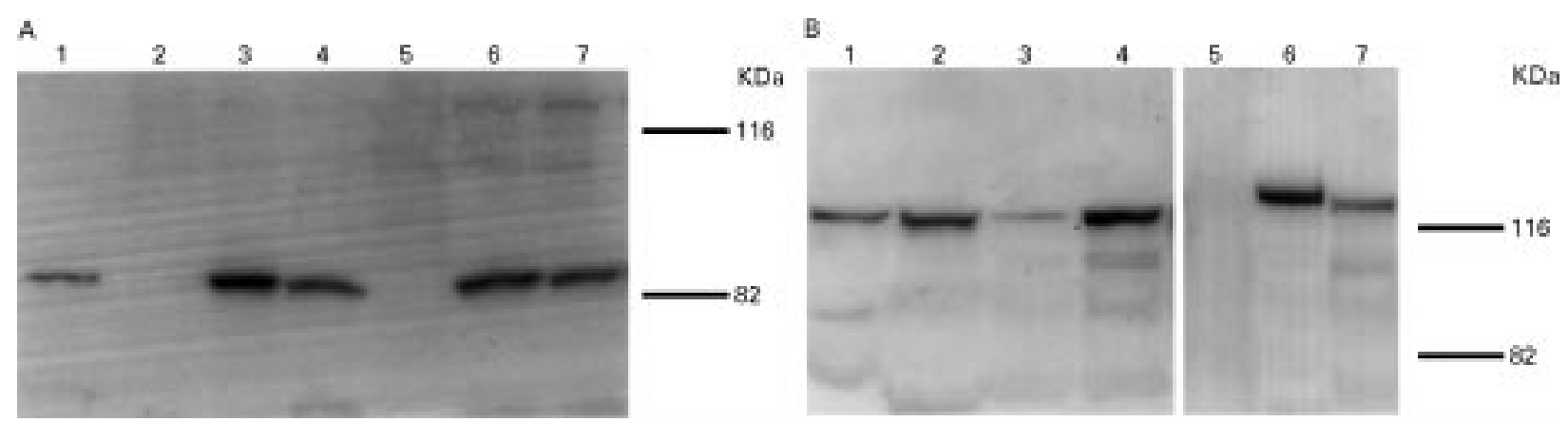

Figure 1 (A) Immunoblot analysis of VacA. Surface proteins obtained from seven $H$ pylori strains were probed with antiserum against the recombinant VacA protein. VacA protein was expressed in T-1 (lane 1), T-5, T-6 (lanes 3 and 4), T-24 and T-39 (lanes 6 and 7), but not in T-48 (lane 2) or T-25 (lane 5). (B) Immunoblot analysis of CagA. Total lysates obtained from seven $H$ pylori strains were probed with antiserum against the recombinant Cag $A$ protein. CagA protein was expressed in T-1, T-48, T-5, T-6 (lanes 1-4), T-24 and T-39 (lanes 6 and 7), but not in T-25 (lane 5). Molecular mass is shown in $k D a$.

anti-VacA ${ }^{25}$ and anti-CagA ${ }^{26}$ antibodies irrespective of the gastroduodenal disease.

Since the presence of antibodies does not necessarily imply on-going infection, our previous studies suggested but did not prove high prevalence of infection with Type I strains in Japan. Therefore we conducted the current study to examine, by immunoblot analysis using specific antibodies raised against recombinant proteins, the expression of VacA and CagA proteins by $H$ pylori isolates obtained from Japanese patients.

All $H$ pylori isolates reported so far were found to possess the vacA gene, and strains without cytotoxin activity are thought to produce inactive cytotoxin and/or have defective secretion mechanisms. ${ }^{27}$ Thus we also examined the vacuolating activity and the genotypes of the vacA gene reported to be associated with the ability to secrete vacuolating cytotoxin.

\section{Materials and methods}

BACTERIAL STRAINS AND GROWTH

$H$ pylori strains were isolated from gastric biopsy samples of 68 patients $(40$ men and 28 women; age range $22-85$ years; mean age 52.5 ) who underwent endoscopy in Tokyo University Hospital. The endoscopic findings were gastric ulcer in 16, duodenal ulcer in 17, non-ulcer dyspepsia in 25, and gastric cancer in 10 patients. Biopsy specimens were cultured on Columbia agar with 5\% horse blood and Dent antibiotic supplement (Oxoid, Basingstoke, Hants, UK) at $37^{\circ} \mathrm{C}$ for five days under microaerobic conditions. Isolates were identified as $H$ pylori by Gram stain morphology and by positive urease, catalase, and oxidase activities. They were kept at $-80^{\circ} \mathrm{C}$ in brucella broth with $5 \%$ fetal bovine serum (FBS) containing 16\% glycerol. ATCC43526 cells were used as VacA and CagA positive controls, and strain Tx30a was used as CagA negative control. ${ }^{25} 26$

RECOMBINANT VACA AND CAgA PROTEINS AND ANTISERA TO RECOMBINANT VACA AND CAGA Recombinant $\operatorname{VacA}^{25}$ and $\operatorname{CagA}^{26}$ proteins and the rabbit antiserum to each recombinant protein were prepared as described previously. In brief, the entire vacA gene (GenBank accession number AF001358) and $\operatorname{cag} A$ gene (GenBank accession number AF001357) of the
ATCC43526 $H$ pylori strain were cloned, and partial fragments of vacA (encoding amino acids 1 , which is the ATG start codon, to 744) and $\operatorname{cag} A$ (encoding amino acids 107-531) genes were subcloned in frame with the sequence coding for the histidine tag of $\mathrm{pQE}$ vectors (Qiagen, Chatsworth, CA, USA). The histidine-tagged VacA and CagA proteins expressed in Escherichia coli were purified on $\mathrm{Ni} /$ nitrilotriacetic acid resin (Qiagen). Antibodies against the recombinant proteins were raised in New Zealand White rabbits.

DETECTION OF VACA and CagA proteins in $H$ PYLORI ISOLATES

Immunoblot analysis was performed to detect VacA and CagA proteins produced by $H$ pylori strains. VacA protein was examined using $H$ pylori surface proteins prepared by the method of Xiang et al. ${ }^{19}$ In brief, the cultured bacterial cells were washed twice with distilled water, and, to separate the surface protein from bacterial cells, vortex mixed with distilled water for one hour at room temperature. After centrifugation at $10000 \mathrm{~g}$ for ten minutes, the supernatants were stored at $-30^{\circ} \mathrm{C}$ until use.

CagA protein was examined using whole cell lysates. The whole cell lysates were washed twice in normal saline and centrifuged, and boiled at $100{ }^{\circ} \mathrm{C}$ for $5 \mathrm{~min}$ in Laemmli sample buffer before use. ${ }^{28}$ The surface proteins and the whole cell lysates were separated by electrophoresis in sodium dodecyl sulphate/ $10 \%$ polyacrylamide gel and transferred to a nitrocellulose membrane (Schleicher \& Schuell, Dassel, Germany). The filter was blocked with buffer containing 5\% skimmed milk in $25 \mathrm{mM}$ Tris/ $\mathrm{HCl}, \mathrm{pH} 7.4$, containing $150 \mathrm{mM} \mathrm{NaCl}$ and $5 \mathrm{mM} \mathrm{KCl}$. The membrane was incubated with a 1:100 dilution of rabbit antiserum against the recombinant VacA or CagA. After being washed, the membrane was incubated with ${ }^{125}$ I-labelled goat anti-rabbit immunoglobulin $\mathrm{G}$, and then exposed to $x$ ray film.

\section{VACUOLATING ASSAY}

$H$ pylori strains were cultured at $37^{\circ} \mathrm{C}$ in brucella broth containing 5\% FBS under microaerobic conditions for 48 hours. The culture medium was centrifuged at $10000 \mathrm{~g}$ for 20 min, and cell-free supernatant was sterilised by passage through a $0.2 \mu \mathrm{m}$ pore size filter and 
Table 1 Helicobacter pylori strains used in this study

\begin{tabular}{|c|c|c|c|c|c|}
\hline \multirow{2}{*}{\multicolumn{2}{|c|}{ Strain * no. }} & \multicolumn{2}{|c|}{ Protein secretion } & \multirow[b]{2}{*}{ Vacuolating assay } & \multirow[b]{2}{*}{ Typet } \\
\hline & & $\operatorname{Vac} A$ & CagA & & \\
\hline \multicolumn{6}{|c|}{ Gastric ulcer } \\
\hline 1 & $(\mathrm{~T}-1)$ & + & + & + & I \\
\hline 2 & (T-6) & + & + & + & I \\
\hline 3 & (T-24) & + & + & + & I \\
\hline 4 & (T-39) & + & + & + & I \\
\hline 5 & $(\mathrm{~T}-72)$ & + & + & + & I \\
\hline 6 & $(\mathrm{~T}-84)$ & + & + & + & I \\
\hline 7 & (T-97) & + & + & + & I \\
\hline 8 & (T-23) & + & + & + & I \\
\hline 9 & (T-59) & + & + & + & I \\
\hline 10 & (T-78) & + & + & + & I \\
\hline 11 & (T-99) & + & + & + & I \\
\hline 12 & (T-48) & - & + & + & I \\
\hline 13 & (T-87) & - & + & + & I \\
\hline 14 & (T-79) & + & + & - & Intermediate \\
\hline 15 & (T-98) & + & + & - & Intermediate \\
\hline 16 & (T-57) & + & - & - & Intermediate \\
\hline \multicolumn{6}{|c|}{ Duodenal ulcer } \\
\hline 17 & $(\mathrm{~T}-10)$ & + & + & + & I \\
\hline 18 & (T-29) & + & + & + & I \\
\hline 19 & (T-54) & + & + & + & I \\
\hline 20 & (T-56) & + & + & + & I \\
\hline 21 & $(\mathrm{~T}-60)$ & + & + & + & I \\
\hline 22 & $(\mathrm{~T}-71)$ & + & + & + & I \\
\hline 23 & (T-74) & + & + & + & I \\
\hline 24 & (T-92) & + & + & + & I \\
\hline 25 & (T-101) & + & + & + & I \\
\hline 26 & (T-9) & + & + & + & I \\
\hline 27 & (T-13) & + & + & + & I \\
\hline 28 & (T-35) & + & + & + & I \\
\hline 29 & (T-63) & + & + & + & I \\
\hline 30 & $(\mathrm{~T}-82)$ & + & + & + & I \\
\hline 31 & $(\mathrm{~T}-12)$ & - & - & + & Intermediate \\
\hline 32 & $(\mathrm{~T}-64)$ & + & - & - & Intermediate \\
\hline 33 & (T-15) & - & + & - & Intermediate \\
\hline \multicolumn{6}{|c|}{ Non-ulcer dyspepsia } \\
\hline 34 & $(\mathrm{~T}-5)$ & + & + & + & I \\
\hline 35 & $(\mathrm{~T}-11)$ & + & + & + & I \\
\hline 36 & (T-17) & + & + & + & I \\
\hline 37 & (T-61) & + & + & + & I \\
\hline 38 & (T-75) & + & + & + & I \\
\hline 39 & (T-76) & + & + & + & I \\
\hline 40 & (T-77) & + & + & + & I \\
\hline 41 & $(\mathrm{~T}-80)$ & + & + & + & I \\
\hline 42 & (T-89) & + & + & + & I \\
\hline 43 & (T-90) & + & + & + & I \\
\hline 44 & (T-111) & + & + & + & I \\
\hline 45 & $(\mathrm{~T}-16)$ & + & + & + & I \\
\hline 46 & (T-73) & + & + & + & I \\
\hline 47 & (T-88) & + & + & + & I \\
\hline 48 & (T-93) & + & + & + & I \\
\hline 49 & (T-100) & + & + & + & I \\
\hline 50 & (T-102) & + & + & + & I \\
\hline 51 & (T-103) & + & + & + & I \\
\hline 52 & (T-94) & + & - & + & Intermediate \\
\hline 53 & (T-53) & + & - & + & Intermediate \\
\hline 54 & $(\mathrm{~T}-47)$ & + & + & - & Intermediate \\
\hline 55 & $(\mathrm{~T}-3)$ & - & + & - & Intermediate \\
\hline 56 & (T-25) & - & - & - & II \\
\hline 57 & $(\mathrm{~T}-85)$ & - & - & - & II \\
\hline 58 & (T-68) & - & - & - & II \\
\hline \multicolumn{6}{|c|}{ Gastric cancer } \\
\hline 59 & $(\mathrm{~T}-7)$ & + & + & + & I \\
\hline 60 & (T-115) & + & + & + & I \\
\hline 61 & (T-116) & + & + & + & I \\
\hline 62 & $(\mathrm{~T}-22)$ & + & + & + & I \\
\hline 63 & (T-26) & + & + & + & I \\
\hline 64 & (T-81) & + & + & + & I \\
\hline 65 & (T-112) & + & + & + & I \\
\hline 66 & (T-113) & + & + & + & I \\
\hline 67 & (T-114) & + & + & + & I \\
\hline 68 & (T-108) & - & + & - & Intermediate \\
\hline Con & & & & & \\
\hline 69 & $(43526)$ & + & + & + & \\
\hline 70 & (Tx30a) & + & - & - & \\
\hline
\end{tabular}

*The strains whose designation starts with a $\mathrm{T}$ were isolated at Tokyo University Hospital. 43526 was ATCC 43526 from American Type Culture Collection and Tx30a was from Texas.

†Type I strains were positive for vacuolating activity and CagA protein. Type II strains were negative for both, and intermediate strains belonged to neither Type I nor Type II.

concentrated 20 -fold by using a $30 \mathrm{kDa}$ ultrafiltration membrane (Amicon, Lexington, MA, USA), then stored at $-80^{\circ} \mathrm{C}$ until use for the vacuolating assay. HeLa cells were cultured in plastic flasks in Dulbeccos' modified Eagle's medium containing $10 \% \mathrm{FBS}$ at $37{ }^{\circ} \mathrm{C}$ in $5 \%$ $\mathrm{CO}_{2}$ atmosphere. Confluent cell cultures were treated with trypsin and adjusted to a concentration of $1 \times 10^{4}$ cells per ml. At 24 hours before the addition of culture supernatant, 100 $\mu \mathrm{l}$ of cells were seeded into each well of a 96-well microtitre plate. A $10 \mu 1$ sample of concentrated supernatant obtained from the culture medium was incubated with the HeLa cells for 24 hours. The result of the vacuolating assay was defined as positive when vacuolation was visible in more than $50 \%$ of HeLa cells by light microscopy.

TYPING OF VAC $A$ GENE BY POLYMERASE CHAIN REACTION (PCR)

The vacA gene encodes a precursor protein made up of amino-terminal signal sequence, the cytotoxin proper, and a membrane protein which is removed during transmembrane transport. Genotyping of $H$ pylori was proposed on the basis of the nucleotide sequence in the signal sequence (types s1a, s1b, and s2) and that in the cytotoxin region $(\mathrm{m} 1, \mathrm{~m} 2)$. We amplified the vacA gene by PCR using previously described genotype-specific primers. ${ }^{27}$ Thermal cycling was at $94{ }^{\circ} \mathrm{C}$ for 30 seconds, $50{ }^{\circ} \mathrm{C}$ for 15 seconds, and $72{ }^{\circ} \mathrm{C}$ for one minute, for a total of 35 cycles. PCR products were analysed by $1 \%$ agarose gel electrophoresis with ethidium bromide staining. ATCC43526 was used as a s1a/m1 control, and Tx30a was used as a s $2 / \mathrm{m} 2$ control.

STATISTICAL ANALYSIS

Fisher's exact probability test and $\chi^{2}$ test were used to test the independence on contingency tables. $p<0.05$ was considered to be statistically significant.

\section{Results}

DETECTION OF VACA PROTEIN BY IMMUNOBLOT VacA protein was detected among the cell surface proteins obtained from 59 of $68(87 \%) H$ pylori isolates (fig 1A, tables 1 and 2). The positive rate was $14 / 16(88 \%)$ in the isolates from patients with gastric ulcer, $15 / 17(88 \%)$ from those with duodenal ulcer, $21 / 25(84 \%)$ from those with non-ulcer dyspepsia, and $9 / 10$ $(90 \%)$ from gastric cancer patients. Statistically, the positive rate of VacA protein was not dependent on the gastroduodenal disease of the host (table 2).

The immunoblot analysis using whole cell lysates detected VacA protein even in the isolates that were negative by immunoblot analysis using cell surface proteins, suggesting that VacA protein was produced by all isolates but its secretion was disturbed in some of them.

\section{VACUOLATING ASSAY}

The vacuolating assay was positive in 54 of 59 $(92 \%)$ VacA positive isolates and three of nine (33\%) VacA negative ones (tables 1 and 2). Although discordant results were found in 8 of $68(12 \%)$ isolates, the correlation between the two assays was strong enough $(\mathrm{p}<0.001)$ to assume that most isolates positive for VacA 
Table 2 Vacuolating activity and expression of VacA and CagA protein in clinical isolates

\begin{tabular}{lccl}
\hline Diagnosis & Vacuolating activity & & \\
\hline Gastric ulcer $(\mathrm{n}=16)$ & $13(81)$ & $14(88)$ & $15(94)$ \\
Duodenal ulcer $(\mathrm{n}=17)$ & $15(88)$ & $15(88)$ & $15(88)$ \\
Non-ulcer dyspepsia $(\mathrm{n}=25)$ & $20(80)$ & $21(84)$ & $21(84)$ \\
Gastric cancer $(\mathrm{n}=10)$ & $9(90)$ & $9(90)$ & $10(100)$ \\
Total $(\mathrm{n}=68)$ & $57(84)$ & $59(87)$ & $61(90)$ \\
\hline
\end{tabular}

Table 3 Typing of vacA gene

\begin{tabular}{lllcc}
\hline & $m 1$ & $m 2$ & Neither & Total \\
\hline s1a & 5 & 2 & 38 & 45 \\
s1b, s2 & 0 & 0 & 0 & 0 \\
Total & 5 & 2 & 38 & 45 \\
\hline
\end{tabular}

protein by the immunoblot analysis did secrete active cytotoxin.

Five strains were positive for VacA protein by immunoblot but negative for the vacuolating assay. These strains may be secretors of inactive cytotoxin similar to the Tx30a strain. Another three isolates were positive for the vacuolating assay but negative by the immunoblot analysis. The reason for this discrepancy is not known, but it may be that substances other than VacA induced vacuolation.

GENOTYPE OF $V A C A$ GENE

The genotype of the vac $A$ signal sequence was determined in 45 isolates, including six that were negative for VacA by both immunoblot and vacuolating assay. Interestingly, the signal sequence in all isolates was of type s1a, which is supposed to represent high vacuolating activity. ${ }^{27}$ The genotype of the mid region was also investigated in 45 isolates, as well as type $\mathrm{m} 1$ in five $(11 \%)$ and type $\mathrm{m} 2$ in two $(4 \%)$. PCR failed to amplify the mid region in the remaining $38(84 \%)$ isolates (table 3$)$.

DETECTION OF CAGA PROTEIN By IMMUNOBLOT The immunoblot analysis detected CagA protein in 61 of $68(90 \%) H$ pylori isolates (fig $1 \mathrm{~B}$, tables 1 and 2 ). The positive rate was $15 / 16$ $(94 \%)$ in the isolates from patients with gastric ulcer, $15 / 17(88 \%)$ from those with duodenal ulcer, $21 / 25$ (84\%) from those with non-ulcer dyspepsia, and 10/10 (100\%) from gastric cancer patients. As in the case of the VacA protein described above, the positive rate of expression of CagA protein was high irrespective of the gastroduodenal disease of the host (table 2).

The estimated molecular mass of the CagA protein visualised by immunoblot varied from 120 to $140 \mathrm{kDa}$. This may indicate its heterogeneity among $H$ pylor $i$ isolates, although we could find no correlation between its molecular mass and the gastroduodenal status of the host.

CORRELATION BETWEEN VACA AND CAGA The expression of CagA protein correlated strongly with that of VacA, as determined by immunoblot $(p=0.005)$, and with vacuolating cytotoxin activity in vitro $(\mathrm{p}=0.002)$. Overall, 54 of $68(79 \%)$ isolates were positive for cytotoxin activity and CagA protein. These isolates are defined as Type I strains in the following text. Type II strains were negative for these assays, and intermediate strains were neither Type I nor Type II.

The prevalence of Type I strains was 14/17 $(82 \%)$ in the isolates from patients with duodenal ulcer, $13 / 16(81 \%)$ from those with gastric ulcer, $18 / 25(72 \%)$ from those with non-ulcer dyspepsia, and 9/10 (90\%) from gastric cancer patients. The prevalence did not differ significantly between the groups.

Three isolates were negative for VacA protein, vacuolating activity, and CagA protein (Type II). The prevalence of these all-negative isolates was $3 / 25(12 \%)$ in patients with non-ulcer dyspepsia and $0 / 43(0 \%)$ in patients with peptic ulcer or gastric cancer. This difference was statistically significant $(\mathrm{p}=0.046)$.

\section{Discussion}

Our current study shows that most $H$ pylori strains isolated in Japan were positive for vacuolating cytotoxin and CagA protein. Indeed, $54 / 68(79 \%)$ isolates were positive for the vacuolating assay and CagA protein and were therefore Type I strains. These results agree with our previous findings that the seropositivity of anti-VacA and anti-CagA antibodies is very high in Japanese patients with $H$ pylori infection. We can conclude that most $H$ pylori strains in Japan produce both VacA and CagA proteins not only in vitro but also in vivo.

Weel et $a l^{24}$ reported that infection with Type I strains was found in $43 / 76(57 \%)$ patients with peptic ulcers, but in only $28 / 76$ (37\%) patients with non-ulcer dyspepsia in the Netherlands. In contrast, the prevalence of infection with Type I strains was $25 / 33(76 \%)$ in patients with peptic ulcers and $18 / 25(72 \%)$ in those with non-ulcer dyspepsia in Japan. Compared with previous reports from Western countries, Type I infection is very common in Japan irrespective of gastroduodenal status of the host. Since there was no significant relation between a particular gastroduodenal disease in the host and the expression of VacA or CagA protein by the isolate, the virulence factors VacA and CagA cannot be used as a discriminator of gastroduodenal diseases in the host.

Recent studies on the $\operatorname{cag} A$ gene in Japan, Korea, and China, have shown that its prevalence is very high and not related to particular gastroduodenal diseases. ${ }^{29-31}$ For example, Pan et $a l^{29}$ reported that 47 of $48(98 \%)$ strains and 35 of $35(100 \%)$ isolates were positive for the cagA gene in Chinese patients with peptic ulcers and gastritis respectively.

However, the current study does not rule out an association between the expression of VacA or CagA protein and the virulence of $H$ pylori. The incidence of gastric cancer is high in Japan, with 38.2 deaths in 100000 people in $1993 .^{32}$ Epidemiological studies have shown that the prevalence of $H$ pylori infection is significantly higher in patients with gastric cancer than in the general population in Japan as well as in other countries. ${ }^{453}$ It is possible that the high prevalence of infection with Type I strains shown in this study is associated with the high incidence of gastric cancer in Japan. In the current study, no patients with gastric cancer were 
infected with VacA and CagA negative strains, suggesting a possibility that the incidence of gastric cancer may be low in the regions where infection with Type I strains is rare. It would require worldwide surveillance to elucidate whether Type I infection is actually related to gastric carcinogenesis. Recombinant proteins may be used in such studies for the examination of serum specific antibodies.

The vacuolating assay and analysis of VacA protein expression produced slightly different results. The difference between vacuolating activity and expression of VacA protein suggests that some strains secreted either inactive cytotoxin or only a small amount of active cytotoxin, so that the cytotoxin was detected by immunoblot analysis but its activity was not detected by the vacuolating assay. Indeed, some strains such as Tx30a secrete inactive cytotoxin, ${ }^{27}$ so that no vacuolation was observed by the vacuolating assay while VacA protein was detected by immunoblot analysis. Three isolates (T-12, T-47, T-87) were positive in the vacuolating assay but negative by immunoblot analysis. It is possible that substances other than VacA induced the vacuolation, or that VacA protein was decomposed. All isolates that were negative by immunoblot analysis of surface proteins showed VacA protein by immunoblot using cell lysates. These results suggest that VacA protein was produced, at least in bacterial cells.

The genotyping of the vacA gene showed genetic diversities between $H$ pylori isolates from Japan and those from Western countries. The signal sequence of the $v a c A$ gene was of the s1 type (s1a subtypes) in all isolates examined in this study, and the mid region of the gene was of neither the $\mathrm{m} 1$ or $\mathrm{m} 2$ type in $38 / 45$ $(84 \%)$ isolates. A recent study reported similar results on the signal sequence in Japanese isolates. ${ }^{34}$ These results were substantially different from the results obtained in Western countries. For example, Atherton et $a l^{27}$ reported that $21 / 23(91 \%)$ isolates from patients with peptic ulcer but only $16 / 33(48 \%)$ isolates from patients without ulcer were of the s1 type. They also reported that the mid region was either of the $\mathrm{m} 1$ or $\mathrm{m} 2$ subtype in 56 isolates, and no other subtypes were found. The distinct genotypes of the vacA gene of isolates in Japan may be associated with functional differences of the VacA protein, and may be a reason for the high incidence of gastric cancer in Japan.

CagA protein was reported to be produced in most cytotoxin positive strains of $H$ pylori. ${ }^{1617}$ We investigated the association between CagA protein expression and vacuolating activity in isolates in Japan. CagA protein expression and vacuolating activity were both present in 54 of 68 strains, and both absent in five of 68 strains. This result indicates that CagA protein is strongly associated with vacuolating cytotoxin activity in Japan as well as in other countries. ${ }^{1617}$

The function of CagA protein is not understood at all. CagA has been thought to be associated with IL-8 induction in the gastric epithelium, and bacterial eradication reduces IL-8 expression and neutrophil infiltration. ${ }^{23}$
However, recent studies have shown that the IL-8 induction may not be directly due to CagA protein, but to the proteins encoded by the genes in the pathogenicity island upstream of the $\operatorname{cag} A$ gene. These proteins may be co-expressed with CagA and therefore CagA may be used as a marker of enhanced virulence. ${ }^{35} 36$

In conclusion, we examined the expression of VacA and CagA proteins by $H$ pylori strains clinically isolated in Japan. The prevalence of infection with strains that express vacuolating cytotoxin and CagA was very high compared with previous reports from Western countries. No significant correlation was found between the expression of these proteins by the isolates and gastroduodenal status of the host. Thus these virulence factors cannot be used as markers to discern the risk of developing serious gastroduodenal disease in the host in Japan. However, it is possible that the high prevalence of infection with these Type I strains contributes to the characteristics of $H$ pylori infection in Japan.

This work was supported by a Grant-in-Aid for Scientific Research from the Ministry of Education, Science, and Culture of Japan. F K is a Research Fellow of the Japan Society for the

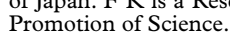

1 Warren JR, Marshall BJ. Unidentified curved bacilli on gastric epithelium in active chronic gastritis. Lancet 1983;1:1273-5.

$2 \mathrm{NIH}$ consensus conference. Helicobacter pylori in peptic ulcer disease. NIH Consensus Development Panel on Helicobacter pylori in Peptic Ulcer Disease. $7 A M A$ 1994;272:65-9.

3 Graham DY, Lew GM, Klein PD, et al. Effect of treatment of Helicobacter pylori infection on the long-term recurrence of gastric or duodenal ulcer: a randomized, controlled study. Ann Intern Med 1992;116:705-8.

4 Parsonnet J, Friedman GD, Vandersteen DP, et al. Helicobacter pylori infection and the risk of gastric carcinoma. N Engl F Med 1991;325:1127-31.

5 Nomura A, Stemmermann GN, Chyou PH, et al. Helicobacter pylori infection and gastric carcinoma among Japanese American in Hawaii. N Engl f Med 1991;325:1132-6.

6 Asaka M, Kimura T, Kudo M, et al. Relationship of Helicobacter pylori to serum pepsinogens in an asymptomatic Japanese population. Gastroenterology 1992;102:760-6.

7 Figura N, Guglielmetti P, Rossolini A, et al. Cytotoxin production by Campylobacter pylori strains isolated from patients with peptic ulcers and from patients with chronic patients with peptic ulcers and from patients
gastritis only. F Clin Microbiol 1989;27:225-6.

8 Fox JG, Correa P, Taylor NS, et al. High prevalence and persistence of cytotoxin-positive Helicobacter pylori strains in a population with high prevalence of atrophic gastritis. Am f Gastroenterol 1992;87:1554-60.

9 Leunk RD. Production of a cytotoxin by Helicobacter pylori. Rev Infect Dis 1991;13:S686-9.

10 Cover TL, Dooley CP, Blaser MJ. Characterization of and human serologic response to proteins in Helicobacter pylori broth culture supernatants with vacuolating cytotoxin activity. Infect Immun 1990;58:603-10.

11 Tee W, Lambert JR, Dwyer B. Cytotoxin production by Helicobacter pylori from patients with upper gastrointestinal tract diseases. F Clin Microbiol 1995;33:1203-5.

12 Cover TL, Blaser MJ. Purification and characterization of the vacuolating toxin from Helicobacter pylori. $\mathcal{F}$ Biol Chem 1992;267:10570-5.

13 Phadnis SH, Ilver D, Weelzon L, et al. Pathological significance and molecular characterization of the vacuolating toxin gene of Helicobacter pylori. Infect Immun 994;62:1557-65.

14 Schmitt W, Haas R. Genetic analysis of the Helicobacter pylori vacuolating cytotoxin: structural similarities with the IgA protease type of exported protein. Mol Microbiol 1994; 12:307-19.

15 Telford JL, Ghiara P, Dell'Orco M, et al. Gene structure of the Helicobacter pylori cytotoxin and evidence of its key role in gastric disease. $\mathcal{F}$ Exp Med 1994;179:1653-8.

16 Covacci A, Censini S, Bugnoli M, et al. Molecular characterization of the 128-kDa immunodominant antigen of Helicobacter pylori associated with cytotoxicity and 7 Tummuru MKR, Cover TL, Blaser MJ. Cloning and expression of a high-molecular-mass major antigen of Helicobacter pylori: evidence of linkage to cytotoxin production. Infect immun 1993;61:1799-809. 
18 Crabtree JE, Figura N, Taylor JD, et al. Expression of 120 kilodalton protein and cytotoxicity in Helicobacter pylori. $\mathcal{F}$ Clin Pathol 1992;45:733-4.

19 Xiang Z, Censini S, Bayeli PF, et al. Analysis of expression of CagA and VacA virulence factors in 43 strains of Helicobacter pylori reveals that clinical isolates can be divided into two major types and that CagA is not
necessary for expression of the vacuolating cytotoxin. Infect necessary for expressio

20 Blaser MJ, Perez-Perez GI, Cover TL, et al. Infection with Helicobacter pylori strains possessing CagA is associated with an increased risk of developing adenocarcinoma of stomach. Cancer Res 1995;55:2111-15.

21 Cover TL, Glupczynski Y, Lage AP, et al. Serologic detection of infection with cagA+ Helicobacter pylori strains. F Clin Microbiol 1995;33:1496-500.

22 Ching CK, Wong BCY, Kwok E, et al. Prevalence of CagAbearing Helicobacter pylori strains detected by the anti-CagA assay in patients with peptic ulcer disease and in anti-CagA assay in patients with peptic ulcer

23 Crabtree JE, Farmery SM, Lindley IKD, et al. CagA cytotoxic strains of Helicobacter pylori and interleukin-8 in gastric epithelial cell lines. F Clin Pathol 1994;47:945-50.

24 Weel JF, van der Hulst RW, Gerrits Y, et al. The interrelationship between cytotoxin-associated gene A vacuolating cytotoxin, and Helicobacter pylori-related diseases. F Infect Dis 1996;173:1171-5.

25 Ogura K, Kanai F, Maeda S, et al. High prevalence of cytotoxin positive Helicobacter pylori in patients unrelevant to the presence of peptic ulcers in Japan. Gut 1997;41:463-8.

26 Maeda S, Kanai F, Ogura K, et al. High seropositivity of anti-CagA antibody in Helicobcter pylori infected patients irrelevant to the presence of peptic ulcers and gastric cancer in Japan. Dig Dis Sci 1997;; 42:1841-7.

27 Atherton JC, Cao P, Peek RJ, et al. Mosaicism in vacuolating cytotoxin alleles of Helicobacter pylori. Association of specific vacA types with cytotoxin production and peptic ation 1 Chem 1995;270:17771-7.

28 Laemmli UK. Cleavage of structural proteins during the assembly of the head of bacteriophage T4. Nature 1970;227:680

29 Pan ZJ, van der Hulst RWM, Feller M, et al. Equally high prevalences of infection with cagA-positive Helicobacter pylori in Chinese patients with peptic ulcer disease and those with chronic gastritis-associated dyspepsia. F Clin Microbiol 1997;35:1344-7.

30 Miehlke S, Kibler K, Kim JG, et al. Allelic variation in the cag $A$ gene of Helicobacter pylori obtained from Korea compared to the United States. Am $\mathcal{f}$ Gastroenterol 1996;91:1322-5.

31 Shimoyama T, Fukuda S. Tanaka M, et al. High prevalence of the CagA-positive Helicobacter pylori strains in Japanese asymptomatic patients and gastric cancer patients. Scand $\mathcal{F}$ asymptomatic patients and gastroenterol 1997;32:465-8.
Gastrot

32 Health and Welfare Statistics Office. Table on mortality. fournal of Health and Welfare Statistics 1995;42:404

33 Asaka M, Kimura T, Kato M, et al. Possible role of Helicobacter pylori infection in early gastric cancer development. Cancer 1994;73:2691-4.

34 Ito Y, Azuma T, Ito S, et al. Analysis and typing of the vacA gene from cagA-positive strains of Helicobacter pylori isolated inJapan. F Clin Microbiol 1997;35:1710-14

35 Tummuru MKR, Sharma SA, Blaser MJ. Helicobacter pylori picB, a homologue of the Bordetella pertussis toxin secretion protein, is required for induction of IL-8 in gastric epithelial cells. Mol Microbiol 1995;18:867-76.

36 Censini S, Lange C, Xiang Z, et al. cag, a pathogenicity island of Helicobacter pylori, encodes type I-specific and disease-associated virulence factors. Proc Natl Acad Sci USA 1996;93:14648-53. 